\title{
An Epidemiological Study of Haemophilus influenzae at a Brazilian Day Care Center
}

Bonifácio da Silva M.E. and Marin J.M.

University of São Paulo, SP, Brazil

\begin{abstract}
Day care centers are a relatively new phenomenon in Brazil that bring together large numbers of young children susceptible to contagious diseases. Haemophilus influenzae (Hi) is an important infection in the age range of those attending day care centers. In the present study, the carriage rate of Haemophilus influenzae was identified in $\mathbf{3 8}$ day care attendees age 6 to 37 months, and 23 staff members, at a day care center in Ribeirão Preto-São Paulo, in 1997. To identify the carriers, two nasopharyngeal swabs were collected; one in July and one in December. The rate of $\boldsymbol{H}$. influenzae carriers among the children was $77 \%$. Only 2 of 23 staff members $(9 \%)$ had Hi. Among the children, there were 58 isolates in the two sampling periods; 6 of the $\mathrm{Hi}$ were serotype $b, 1$ was serotype e, and 48 isolates were non-typeable. Two were identified as $H$. parainfluenzae. One adult had a non-typeable $\mathrm{Hi}$ and $1 \mathrm{had} \boldsymbol{H}$. paraphrohaemolyticus. Three of the 6 children with type $B$ had received a conjugate vaccine against $H$. influenzae type b, but they still carried this bacterium in the nasopharynx $(50 \%)$. Forty ribotype patterns were found among the isolates, showing a high exchange rate of nontypeable $\mathrm{H}$. influenzae carriers. The results indicate that, because of the high and changing biotype of $\mathrm{Hi}$ carriage, day care centers should be carefully monitored as potential point source of $\mathrm{HI}$ disease in the community.

Key Words: Haemophilus influenzae, day care, colonization.
\end{abstract}

Haemophilus influenzae (Hi) is a Gram negative coccobacillus which asymptomatically colonizes the nasopharynx of healthy individuals and, occasionally, causes systemic disease and mucous membrane infections [1]. Strains of $\mathrm{Hi}$ are classified according to their polysaccharide capsule. There are six structurally and antigenically distinct capsular serotypes designated from a to $\mathrm{f}$, and nonencapsulated (nontypeable) strains [2].

More than $90 \%$ of systemic diseases are caused by Hi type b (Hib). The availability of a vaccine based on the type b capsular antigen has dramatically reduced

Received on 19 January 2001; revised 4 October 2001.

Address for correspondence: Dr. José Moacir Marin. Departamento de Morfologia, Estomatologia e Fisiologia Universidade de São Paulo Campus Ribeirão Preto, Av do Café S/N ${ }^{\circ}$ Campus USP, CEP 14040-904, Ribeirão Preto, São Paulo, Brazil.

The Brazilian Journal of Infectious Diseases 2001;5(5):260-268 (C) 2001 by The Brazilian Journal of Infectious Diseases and Contexto Publishing. All rights reserved.

1413-8670 the incidence of such diseases in Europe [3], North America [4], and, more recently, in developing countries like Gambia [5]. The incidence of diseases caused by nonencapsulated $H i$ is still significant [6].

Nontypeable $\mathrm{Hi}(\mathrm{NTHi})$ is a frequent cause of local infections such as otitis media, conjunctivitis, and sinusitis in children [7]. Some data suggest that NTHi is a significant cause of invasive diseases, such as pneumonia, in children in developing countries [7] and pneumonia, septicemia, and meningitis in adults [8]. Although this pathogen is associated with a variety of infections, it is also frequently isolated from the upper respiratory tract of healthy children with reported carrier rates of up to $60 \%$ [9]. The significance of nasopharyngeal colonization by NTHi is unclear, but colonization has been shown to be associated with an increased risk of developing acute otitis media and conjunctivitis in children attending day care centers [10].

Nasopharyngeal colonization with $\mathrm{Hi}$, which precedes $H i$ infection and disease, is a dynamic process [11]. A possible explanation for prolonged $\mathrm{Hi}$ carriage 
includes the known ability of the bacteria to persist intracellularly [12], the induction of a weak inflamatory response by $H i$ carriage [13], and the presence of antigenic variation among colonizing $\mathrm{Hi}$ strains [14].

In Brazil, until recently (1999), Hib vaccination was not part of the national immunization program, even though some cities widely use the Hib vaccine [15].

The aims of the present six month day care population-based study were to examine the carriage rate of $\mathrm{Hi}$ in the nasopharynx of healthy children 6 to 37 months of age and their caretakers; to identify the biotypes and serotypes of the isolates; to assess possible relationships among isolates by ribotyping with the pKK3535 plasmid (rRNA operon); and to investigate the effect of vaccination against $\mathrm{Hib}$ on nasopharynx colonization by $\mathrm{Hib}$.

\section{Material and Methods}

\section{$\underline{\text { Sample collection }}$}

Samples were collected in July and December, 1997, at the Carochinha, a day care center on the São Paulo University Campus, Ribeirão Preto. Attendees were grouped by age into three modules: Pink - infants (aged 6 to 20 months), Green - toddlers (aged 19 to 37 months) and Blue - preschool group (aged 33 to 66 months). Due to the day care work schedule, each module was subdivided into four subgroups of 5 to 7 children and 1 or 2 staff members were responsible for alimentation, recreation, and hygiene in each subgroup. Only the Pink (subgroups A, B, C, D ) and Green (subgroups E, F, G, H ) modules were evaluated in this study. $\mathrm{Hi}$ colonization was investigated in 38 children aged 6 to 37 months attending the day care center, and 23 staff members. In July and December, a single nasopharyngeal swab was obtained from each child and staff member studied. The Ethics Committees in charge of health care for the day care center approved the research protocol. Signed informed consent was obtained for each child from a parent or guardian.
Nasopharyngeal swab specimens were collected by inserting a flexible swab (Culture Swab Transport System, Difco laboratories, Detroit, MI, USA) through the nares until the posterior pharynx was reached. The swab was then rotated for $1-2 \mathrm{sec}$ and withdrawn. Swabs were placed in transport medium (Stuart, modified) and carried to the laboratory to be processed on the same day.

\section{Bacterial culture and identification}

Swabs were streaked on chocolate agar plates to isolate $\mathrm{Hi}$, and the plates were then incubated for 24 to 48 hours at $35^{\circ} \mathrm{C}$ in an atmosphere containing $5 \% \mathrm{CO}_{2}$. Colonies suspected of being Haemophilus were confirmed by Gram's staining and their requirement for $\mathrm{V}$ and $\mathrm{X}$ factors for growth. Species and biotypes were identified in each isolate as described by Kilian and Biberstein [16]. The latex-agglutination technique with antiserum was used to identify serotypes a to $\mathrm{f}$ (Difco).

\section{Bacterial strains}

The strains used were NCTC 7279 for wild type Hib and Escherichia coli DH5 $\alpha$ for plasmid propagation. Isolates were stored on a long-term basis at $-70{ }^{\circ} \mathrm{C}$ in supplemented brain heart infusion broth containing $80 \%$ glycerol $(1: 1)$.

\section{DNA probes}

Plasmid pKK3535 (11.8Kb) [17] was provided by Irma Rivera (Biomedical Institute, São Paulo University, Brazil). This plasmid contains the entire rRNA operon $(5 \mathrm{~S}, 16 \mathrm{~S}, 23 \mathrm{~S})$ of the E. coli chromosome.

\section{DNA preparation}

High-molecular-weight chromosomal DNA was extracted from $\mathrm{Hi}$ isolates [18]. Plasmid DNA was isolated by the alkaline lysis method [19]. 
$\underline{\text { Southern analyses of genomic DNA }}$

Genomic DNA ( $3 \mu \mathrm{g}$ ) was fully digested with HindIII (Bethesda Research Laboratories, Gaithersburg, MD, U.S.) according to manufacturer instructions, eletrophoresed on $0.7 \%$ agarose-Tris acetate gels, and transferred to nylon membranes. Nick translation and Southern hybridization were performed by standard techniques [19]. Ribotyping for $16 \mathrm{~S}$ and $23 \mathrm{~S}$ was done by a method described before [20] and using the pKK 3535 plasmid [17].

\section{Results}

Culture specimens were obtained from 38 children and 23 day care staff members who agreed to participate in the study. This subpopulation comprised $61 \%$ of the total number of children enrolled at the center and $88 \%$ of the day care staff. The nasopharyngeal cultures were positive for $\mathrm{Hi}$ in 28 of 37 children $(75.6 \%)$ in July, and in 30 of 38 children (78.9\%) in December. For the adult staff members, only 1 of 23 (4.35\%) in July, and 1 of 23 (4.35\%) in December were positive for Haemophilus.

A total of 60 isolates were biotyped and serotyped. The adult staff member isolate recovered in July was an Hi biotype II, and the isolate recovered in December was $H$. paraphrohaemolyticus. The $H i$ serotypes recovered from children in July were serotypes $b$ (child 18) and e (child 21), but in December, only serotype b was found (children 12, 22, 23, 35 and 37) (Table 1). The capsule-type b strains were biotype I in July, and biotype I, II, and V in December (Table 1). Except for the $\mathrm{Hi}$ isolate with the above serotype and the recovered $H$. parainfluenzae, all other strains were NTHi isolates.

In July, the predominant biotypes found among the $H i$ isolates were II (39\%), V (25\%) and I (21\%). In December, the variability increased and only biotype III was found at a high percentage (30\%), while other species such as $H$. parainfluenzae were recovered (Table 2).
The rRNA genes were visualized by probing with the radioactive labeled plasmid pKK3535 DNA. Digestion with Hind III restriction enzyme resulted in 10 main bands of $18,8.8,7.8,5.8,4.8,3.7,2.4$, $2.1,1.9$ and $1.1 \mathrm{~Kb}$. After Hind III cleavage, the strains could be differentiated into 40 ribotype patterns and grouped. Table 3 shows the variability of ribotypes from the isolates collected in July and December. Thirteen patterns were found with more than 1 isolate, and 27 other patterns were found only once and were designated variable. Among the 28 $H i$ isolates from the first collection (July), 19 (68\%) showed a ribotype pattern present in more than 1 strain, ribotype I was recovered from different subgroups, and ribotype IV was recovered at highest incidence from the same subgroup. Only ribotype $\mathrm{V}$ was found in both July and December.

\section{Discussion}

Bacteria present in the nasopharynx of normal children reflect the strains currently circulating in the community and causing infections. Therefore, study of the prevalence of these bacteria can provide useful information.

With the exception of limited data available from studies of Hib strains recovered in restricted settings in Brazil and Chile [21], little is known about the nature of strains cultured from patients in South America. Analysis of the available data indicates that South America does not differ significantly from other geographic regions $[15$, 22], and, until recently, the incidence and scope of $H \mathrm{ib}$ diseases appear to be similar to those observed in the United States [23] and Europe [24].

The prevalence of nasopharyngeal $\mathrm{Hi}$ at the day care center investigated was quite high $(77 \%)$ when compared with the nasopharyngeal frequency among Italian children [25], but was similar to colonization rates reported for American children [26]. The biotypes isolated, I, II and III, agree with those reported by others [27].

Spinola [28] found that children were usually colonized by a strain of NTHi for several months, which was then substituted by a new strain, indicating that the 
Table 1. Biotypes and serotypes of Haemophilus influenzae isolated from the nasopharynx of children at a day care center

\begin{tabular}{|c|c|c|c|c|c|}
\hline Child & Group & $\begin{array}{l}\text { Age in } \\
\text { months }\end{array}$ & $\begin{array}{l}\text { Doses of } \\
\text { conjugate } \\
\text { vacine }\end{array}$ & $1^{\text {st }}$ collection & $2^{\text {nd }}$ collection \\
\hline 1 & A & 6 & 0 & Neg. & Neg. \\
\hline 2 & A & 6 & 1 & Neg. & Neg. \\
\hline 3 & B & 9 & 0 & I & VI \\
\hline 4 & B & 9 & 0 & V & III \\
\hline 5 & $\mathrm{C}$ & 10 & 0 & I & parainfluenzae I \\
\hline 6 & $\mathrm{C}$ & 10 & 0 & V & Neg. \\
\hline 7 & $\mathrm{C}$ & 11 & 0 & I & VI \\
\hline 8 & $\mathrm{C}$ & 11 & 0 & Neg. & Neg. \\
\hline 9 & $\mathrm{C}$ & 11 & 0 & Neg. & Neg. \\
\hline 10 & $\mathrm{C}$ & 12 & 0 & I & Neg. \\
\hline 11 & $\mathrm{D}$ & 15 & 0 & III & I \\
\hline 12 & D & 18 & 0 & II & $\mathrm{Vb}$ \\
\hline 13 & D & 19 & 0 & V & II \\
\hline 14 & D & 19 & 3 & Neg. & I \\
\hline 15 & D & 20 & 1 & III & II \\
\hline 16 & $\mathrm{E}$ & 19 & 3 & II & Neg. \\
\hline 17 & $\mathrm{E}$ & 21 & 0 & II & III \\
\hline 18 & $\mathrm{E}$ & 21 & 0 & $\mathrm{Ib}$ & III \\
\hline 19 & $\mathrm{E}$ & 22 & 2 & V & IV \\
\hline 20 & $\mathrm{~F}$ & 23 & 0 & II & II \\
\hline 21 & $\mathrm{~F}$ & 23 & 0 & IVe & V \\
\hline 22 & $\mathrm{~F}$ & 23 & 0 & II & $\mathrm{Ib}$ \\
\hline 23 & $\mathrm{~F}$ & 23 & 2 & n.c & $\mathrm{Ib}$ \\
\hline 24 & $\mathrm{G}$ & 29 & 0 & II & III \\
\hline 25 & $\mathrm{G}$ & 29 & 0 & I & V \\
\hline 26 & $\mathrm{G}$ & 31 & 0 & I & V \\
\hline 27 & $\mathrm{G}$ & 31 & 1 & II & parainfluenzae II \\
\hline 28 & G & 34 & 1 & II & III \\
\hline 29 & $\mathrm{G}$ & 34 & 0 & II & III \\
\hline 30 & $\mathrm{G}$ & 34 & 0 & V & II \\
\hline 31 & $\mathrm{H}$ & 32 & 0 & Neg. & Neg. \\
\hline 32 & $\mathrm{H}$ & 36 & 0 & II & III \\
\hline 33 & $\mathrm{H}$ & 36 & 0 & V & IV \\
\hline 34 & $\mathrm{H}$ & 36 & 1 & Neg. & III \\
\hline 35 & $\mathrm{H}$ & 36 & 1 & Neg. & IIb \\
\hline 36 & $\mathrm{H}$ & 37 & 0 & II & I \\
\hline 37 & $\mathrm{H}$ & 37 & 1 & V & IIb \\
\hline 38 & $\mathrm{H}$ & 37 & 1 & Neg. & III \\
\hline
\end{tabular}

Different modules inside day care.

A,B,C,D,E,F,G,H: subgroups inside modules; I,II,III,IV,V,VI: biotypes of Haemophilus; b, e: serotypes of Haemophilus influenzae; Nc: not collected; Neg: without positive isolation. 
Table 2. Percentage of various biotypes of Haemophilus influenzae and Haemophilus parainfluenzae isolated at the first and second collection from the nasopharynx of children at a day care center

\begin{tabular}{lcc}
\hline Haemophilus & $\begin{array}{c}\mathbf{1}^{\text {st }} \\
(\mathbf{n = 2 8})\end{array}$ & $\begin{array}{c}\mathbf{2}^{\text {nd }} \mathbf{c o l l} \\
(\mathbf{n = 3 0 )}\end{array}$ \\
\hline influenzae biotype I & 21 & 10 \\
influenzae biotype Ib & 4 & 7 \\
influenzae biotype II & 39 & 13 \\
influenzae biotype IIb & & 7 \\
influenzae biotype III & 7 & 30 \\
influenzae biotype IV & & 7 \\
influenzae biotype IVe & 4 & \\
influenzae biotype V & 25 & 3 \\
influenzae biotype Vb & & 7 \\
influenzae biotype VI & & 3 \\
parainfluenzae biotype I & & 3 \\
parainfluenzae biotype II & & \\
\hline
\end{tabular}

* Percentage of positive isolates.

Table 3. Distribution of ribotypes found with the pKK3535 probe after cleavage by HindIII

\begin{tabular}{|c|c|c|c|c|c|c|c|c|c|c|c|c|c|c|c|c|c|c|}
\hline Group & & & & & & C & I & D & & E & & $=$ & ( & G & I & H & $\begin{array}{l}\text { Tot } \\
\text { chil }\end{array}$ & \\
\hline Collection & $1^{\text {st }}$ & $2^{\text {nd }}$ & $1^{\text {st }}$ & $2^{\text {nd }}$ & $1^{\text {st }}$ & $2^{\text {nd }}$ & $1^{\text {st }}$ & $2^{\text {nd }}$ & $1^{\text {st }}$ & $2^{\text {nd }}$ & $1^{\text {st }}$ & $2^{\text {nd }}$ & $1^{\text {st }}$ & $2^{\text {nd }}$ & $1^{\text {st }}$ & $2^{\text {nd }}$ & $1^{\text {st }}$ & $2^{\text {nd }}$ \\
\hline \begin{tabular}{|l} 
Similar \\
Ribotype I
\end{tabular} & & & $\Delta$ & & & & $\Delta$ & & $\Delta$ & & & & $\Delta$ & & & & 4 & 0 \\
\hline \begin{tabular}{|l|} 
Similar \\
Ribotype II
\end{tabular} & & & & $\Delta$ & & & & & & & & $\Delta$ & & & & & 0 & 2 \\
\hline \begin{tabular}{|l|} 
Similar \\
Ribotype III
\end{tabular} & & & & & $\Delta \Delta$ & & & & & & & & & & & & 2 & 0 \\
\hline \begin{tabular}{|l|} 
Similar \\
Ribotype IV
\end{tabular} & & & & & $\Delta$ & & $\Delta \Delta \Delta$ & & & & & & & & & & 4 & 0 \\
\hline \begin{tabular}{|l|} 
Similar \\
Ribotype V
\end{tabular} & & & & & & & & $\Delta$ & & & $\Delta$ & & $\Delta$ & & $\Delta$ & & 2 & 1 \\
\hline \begin{tabular}{|l|} 
Similar \\
Ribotype VI
\end{tabular} & & & & & & & & & $\Delta$ & & & & & & & & 2 & 0 \\
\hline \begin{tabular}{|l|} 
Similar \\
Ribotype VII
\end{tabular} & & & & & & & & & & & $\Delta$ & & $\Delta$ & & & & 2 & 0 \\
\hline \begin{tabular}{|l|} 
Similar \\
Ribotype VIII
\end{tabular} & & & & & & & & & & & $\Delta$ & & $\Delta \Delta$ & & & & 3 & 0 \\
\hline \begin{tabular}{|l|} 
Similar \\
Ribotype IX
\end{tabular} & & & & & & & & & & & & & & $\Delta \Delta$ & & & 0 & 2 \\
\hline \begin{tabular}{|l|} 
Similar \\
Ribotype X
\end{tabular} & & & & & & & & & & & & & $\Delta$ & & & $\Delta$ & 0 & 2 \\
\hline \begin{tabular}{|l|} 
Similar \\
Ribotype XX
\end{tabular} & & & & & & & & & & & & & & $\Delta$ & & $\Delta$ & 0 & 2 \\
\hline \begin{tabular}{|l|} 
Similar \\
Ribotype XII
\end{tabular} & & & & & & & & & & & & & & & & $\Delta \Delta$ & 0 & 2 \\
\hline \begin{tabular}{|l|} 
Similar \\
Ribotype XIII
\end{tabular} & & & & & & & & & & & & & & & & $\Delta$ & 0 & 1 \\
\hline \begin{tabular}{|l} 
Variable \\
Ribotypes
\end{tabular} & & & $\Delta$ & $\Delta$ & $\Delta$ & $\Delta \Delta$ & & $\Delta \Delta \Delta \Delta \mid$ & $\Delta \Delta$ & $\Delta \Delta \Delta$ & & $\Delta \Delta \Delta$ & $\Delta \Delta$ & $\Delta \Delta \Delta$ & $\Delta \Delta \Delta$ & $\Delta \Delta$ & 9 & 18 \\
\hline $\begin{array}{l}\text { Total strains } \\
1^{\text {st }} \text { col. }\end{array}$ & 0 & & 2 & & 4 & & 4 & & 4 & & 3 & & 7 & & 4 & & 28 & \\
\hline $\begin{array}{l}\text { Total stratins } \\
2^{\text {nd }} \mathrm{col} \text {. }\end{array}$ & & 0 & & 2 & & 2 & & 5 & & 3 & & 4 & & 7 & & 7 & & 30 \\
\hline
\end{tabular}

*A, B, C, D (infants- aged 6 to 20 months), E, F, G, H ( toddlers- aged 19 to 37 months): subgroups of children at the day-care center; ${ }^{* *}$ I to XIII : ribotypes found more than once; $* * *$ variable ribotypes: ribotype found only once; $\Delta$ : one child. 
loss and acquisition of strains was a common event. Our data confirm this observation because most of the children showed a different biotype strain in the first compared to the second collection (Table 1).

$H i$ is carried in the throats of most healthy adults and can be spread by droplet infection [29]. Surprisingly, we recovered only two $H i$ isolates from two different day care staff members (one in July, and one in December), even though we examined swabs from 23 adults each time. This was unexpected because high $\mathrm{Hi}$ carriage rates have been described in adults, especially NTHi strains [30]. Neither strain recovered was similar to those recovered from the children (data not shown). An explanation for the small number of isolates recovered from the adults could be the sampling method. Coen, et al. [31], found that oropharyngeal cultures are more sensitive than nasopharyngeal cultures.

We also investigated the source of variation detected in traditional probe-based ribotyping patterns of NTHi. Previous ribotyping studies of $H i$ showed that $E c o$ RI or HindIII gave the most discriminating patterns [32]. Jordens and Leaves [33] reported that traditional 16S+ 23S rRNA remains the standard for epidemiological investigation of NTHi. We found 40 different ribotypes, 13 of them recovered from more than 1 isolate, while 27 other ribotypes were found only once (Table 3 ). The results suggest a high level of strain shift between July and December.

Very young infants are protected against $H i$ b by passively-acquired maternal antibodies. However, after the first few months of life, the incidence of Hib infection rises dramatically, with a peak incidence between 6 and 11 months of age. This incidence then falls slowly in parallel to the development of naturally occuring antibodies so that, by about 2 years of age, the incidence has fallen sharply and, by 5 years of age, the age-specific incidence begins to level off at a relatively constant low level [34].

Pharyngeal colonization by $\mathrm{Hib}$ is present in less than $5 \%$ of healthy preschool children who have not been exposed to a patient with systemic disease [35]. In contrast, carrier rates as high as $50 \%$ have been found in preschool children who attend day care centers in which one or more individuals with Hib disease were present [36]. Limited information is available describing the natural history of Hib colonization among children in day care in the absence of invasive disease. Turk [37] reported that $9(11 \%)$ of 85 healthy preschool children at a day care nursery without disease were colonized by $H i b$. We found almost the same frequency $(12 \%)$ of $H i b$, but with a difference; i.e., 3 children (25\%) had already received one or two doses of vaccine and were considered adequately immunized against Hib [15].

In Brazil, three vaccines were released for use in two-month-old infants; the Act-HIB (Pasteur-Mérieux, Lyon, France), the HibTITER (HbOC Wyeth-Lederle, Pearl River, NY, USA) and the PedvaxHIB (PRPOMP Merck Sharp and Dohme, West Point, Pennsylvania, USA). Act-HIB and HibTITER should be administered at 2, 4, and 6 months, with a booster dose at 15 months, and the PedvaxHIB should be administered at 2 and 4 months with a booster dose at 12 months. For those vaccinated after age 12 months, a single dose of any vaccine should be administered [38]. The use of a booster dose is a controversial question and, in the United Kingdom and the Republic of Ireland, the booster dose is not administered [39]. Children $<1$ year of age are considered adequately immunized against $H i b$ if, prior to testing, they have received 3 doses of vaccine (when immunization begins before age 6 months) or 2 doses (when immunization begins between 7 and 12 months of age). For those vaccinated after age 12 months, a single injection is considered satisfactory.

Children 23, 35 and 37 (Table 1) were considered to have been immunized against $H i b$, but they still carried $H i b$ strains in their nasopharynx. The observation that $H i b$ is still circulating in the community is a cause of concern. If $H i b$ vaccination levels fall, existing Hib clones could spread more widely and cause an increase in Hib disease [40].

The incidence of Hib disease in Brazil is difficult to evaluate [41], and only cases of meningitis could be adequadely evaluated. Still, the numbers obtained are confusing and are probably underestimated. Personal information obtained from the Regional Health Office 
of Ribeirão Preto indicated that a small number of cases (less than 2/100 cases) of meningitis were caused by $H i$ b each year.

In many countries where Hib conjugate vaccines have been introduced, there has been a dramatic reduction in the incidence of $H i b$ disease [3, 5, 4245]. This reduction was often more marked than could be attributed to the direct effect of vaccination and included protection from disease in age groups not included in the vaccination program. This has been attributed to a herd protective effect achieved through a reduction in carriage [5]. The herd protective effect was not detected in the present study, probably because the population evaluated was small or because the time of observation was too short.

Day care provides a potential environment for high rates of acquisition of $\mathrm{Hib}$, even in the absence of invasive disease [46]. The rates of carriage found in the present study reinforce the necessity for constant monitoring to be sure that the national program of Hib immunization introduced in August, 1999, has impacted the carriage as well as disease rates.

\section{Acknowledgements}

We thank Mrs. Ana Maria Mello, Director of the day care center, for permitting us to conduct the study and for obtaining informed consent from the parents of enrolled children. We are indebted to Mrs. Suzel Nogueira Neme and Mr. Paulo da Silva, Instituto Adolfo Lutz, for laboratory assistance, to Irma Rivera, Biomedical Institute, São Paulo University, for providing the plasmid pKK3535, and to Electra Green for reviewing the manuscript.

\section{References}

1. Turk D.C., Clinical importance of Haemophilus influenzae: 1981. In: Sell, S.H., Wright, P.F.eds. Haemophilus influenzae: Epidemiology, Immunology, and Prevention of Diseases. New York: Elsevier, 1982.
2. Pittman M. Variation and type specificity in the bacterial species Haemophilus influenzae. J Exp Med 1931;53:471-95.

3. van Alphen L., Spanjaard L., van Derende A., et al. Effect of nationwide vaccination of 3-month-old infants in the Netherlands with conjugate Haemophilus influenzae type b vaccine: high efficacy and lack of herd immunity. J Pediatr 1997;131:869-73.

4. Liptak G.S., McConnochie K.M., Roghmann K.J., Panzer J.A. Decline of pediatric admissions with Haemophilus influenzae type b in New York State, 1982 through 1993: relation to immunizations. J Pediatr 1996;130:923-30.

5. Adegbola A.A., Mulholland E.K., Secka O., Jaffar S., Greenwood, B.M. Vaccination with a Haemophilus influenzae type $\mathrm{b}$ conjugate vaccine reduces oropharyngeal carriage of $H$. influenzae type $b$ among Gambian children. J Infect Dis 1998; 177:1758-61.

6. Klein J.O. Role of nontypeable Haemophilus influenzae in pediatric respiratory tract infection. Pediatr Infect Dis J 1997; 16:5-8.

7. Foxwell A.R., Kyd J.M., Cripps A.W. Nontypeable Haemophilus influenzae pathogenesis and prevention. Microbiol Mol Biol Rev 1998;62:294-308.

8. Farley M.M, Stephens D.S., Brachaman P.S., et al. Invasive Haemophilus influenzae disease in adults: a prospective, population-based surveillance. Ann Inter Med 1992;116:806-12.

9. Kuklinska D., Kilian M. Relative proportions of Haemophilus influenzae in the throat of healthy children and adults. Eur J Clin Microbiol 1984;3:24952.

10. Henderson F.W., Collier A.M., Sanyal M.A., et al. A longitudinal study of respiratory viruses and bacteria in the etiology of acute otitis media with effusion . N Engl J Med 1982; 306: 1377-83.

11. Trotier S., Stenberg K., Svanborg-Eden C. Turnover of non-typeable Haemophilus influenzae in the nasopharynges of healthy children. J Clin Microbiol 1989;27:2175-9.

12. Forsgren J., Samuelson A., Ahlin A., et al. Haemophilus influenzae resides and multiplies intracellularly in human adenoid tissue as demonstrated by in situ hybridization and bacterial viability assay. Infect Immun 1994;62:673-9.

13. Bresser P., van Alphen L., Habets F.J., et al. Persisting Haemophilus influenzae strains induce lower levels of interleukin-6 and interleukin-8 in H292 lung epithelial cells than nonpersisting strains. Eur Respir 1997; 10:2319-26.

14. Brunham R.C., Plummer F.A., Stephens R.S. Bacterial antigenic variation, host immune response, and pathogen-host coevolution. Infect Immun 1993;61:2273-6. 
15. Forleo-Neto E., de Oliveira C.F., Maluf E.M., et al. Decreased point prevalence of Haemophilus influenzae type $b$ (Hib) oropharyngeal colonization by mass immunization of Brazilian children less than 5 years old with Hib Polyribosylribitol phosphate polysaccharidetetanus toxoid conjugate vaccine in combination with diphtheria-tetanus toxoid-pertussis vaccine. J Infect Dis 1999; 180:1153-8.

16. Kilian M., Biberstein E.L. Genus Haemophilus In: Krieg, N.R., Holt, J.G. eds. Bergey's Manual of Systematic Bacteriology. Baltimore: Williams \&Wilkins, 1984.

17. Grimont F., Grimont P.A.D. Ribosomal ribonucleic acid gene restriction patterns as potential taxonomic tools. Ann Inst. Pasteur Microbiol. 1986; 137:165-75.

18. Pitcher D.G., Saunders N.A., Owen R.J. Rapid extraction of bacterial genomic DNA with guanidine thiocyanate. Lett Appl Microbiol 1989;8:151-6.

19. Sambrook J., Fritsch E.F., Maniatis T. Molecular cloning: a laboratory manual. Cold Spring Harbor, Laboratory Press, 1989.

20. Irino K., Grimont F, Casin I., et al. rRNA gene restriction patterns of Haemophilus influenzae biogroup aegyptius strains associated with Brazilian Purpuric Fever. J Clin Microbiol 1988;26:1535-8.

21. Musser J.M., Kapur V. Molecular population, genetics of Haemophilus influenzae. In: Ellis, R.W., Granoff, D.M. eds. Development and clinical uses of Haemophilus b vaccine.New York, Marcel Dekker, 1994.

22. Peltola H. Haemophilus influenzae type b disease and vaccination in Latin America and the Caribbean. Pediatr Infect Dis J 1997; 16:780-5.

23. Ward J.I. Is Haemophilus influenzae type b disease preventable? JAMA 1985;253:554-6.

24. Peltola H., Rod T.O., Jonsdottir K., et al. Life-threatening Haemophilus influenzae infections in Scandinavia: a five country analysis of the incidence and the main clinical and bacteriologic characteristics. Rev Infect Dis 1990;12:708-15.

25. Principi N., Marchisio P., Schito G.C., et al. Risk factors for carriage of respiratory pathogens in the nasopharynx of healthy children. Pediatr Infect Dis J 1999; 18:517-23.

26. Faden H., Duffy L., William A., et al. Epidemiology of nasopharyngeal colonization with nontypeable Haemophilus influenzae in the first 2 years of life. J Infect Dis 1995; 172:132-5.

27. Oberhofer F.R., Back A.E. Biotypes of Haemophilus influenzae encoutered in clinical laboratories. J Clin Microbiol 1979; 10:168-74.

28. Spinola S.M., Peacock J., Denny F.W., et al. Epidemiology of colonization by nontypeable Haemophilus influenzae in children: a longitudinal study. J Infect Dis 1986; $154: 100-8$.
29. Moxon E.R. Haemophilus influenzae. In: Mandel G.L., Bennet J.E., Dohn R. [eds.] Principles and practice of infectious diseases. 4th ed. New York, Churchill Livingstone, 1995.

30. Sarangi J., Cartwright K., Stuart J., et al. Invasive Haemophilus influenzae diseases in adults. Immunol Infect 2000; 124:441-7.

31. Coen P.G., Heath P.T., Garnet G.P. The Hib immunization programme in the Oxford region: an analysis of the impact of vaccine administration on the incidence of disease. Epidemiol Infect 1999;123:389-402.

32. Bruce K.D., Jordens J.Z. Characterization of noncapsulate Haemopilus influenzae by whole-cell polypeptide profiles, restriction endonuclease analysis and rRNA gene restriction patterns. J Clin Microbiol 1991;29:291-6.

33. Jordens J.Z., Leaves N.I. Source of variation detected in ribotyping patterns of Haemophilus influenzae: comparison of traditional ribotyping, PCR-ribotyping and rDNA restrictrion analysis. J Med Microbiol 1997;46:763-72.

34. Shapiro E.D., Ward J.L. The epidemiology and prevention of disease caused by Haemophilus influenzae type b. Epidemiol Rev 1991;13:113-42.

35. Michaels R.H., Poziviak C.S., Stonebraker F.E., Norden C.W. Factors affecting pharyngeal Haemophilus influenzae type $\mathrm{b}$ colonization rates in children. J Clin Microbiol 1976;4:413-7.

36. Granoff D.M., Gilsdorf J., Gessert C.E., Lowe L. Haemophilus influenzae type $\mathrm{b}$ in a day care center: Relationship of nasopharyngeal carriage to development of anticapsular antibody. Pediatrics 1980;65:65-9.

37. Turk D.C. Nasopharyngeal carriage of Haemophilus influenzae type b. J Hyg 1963;61:247-56.

38. Weckx L.Y., Carvalho E.S. Calendário vacinal: dinâmica e atualização. J Pediatria 1999;75:149-54.

39. Heath P.T., Booy R., Griffiths H., et al. Clinical and immunological risk factors associated with Haemophilus influenzae type b conjugate vaccine failure in childhood. Clin Infect Dis 2000;31:973-80.

40. Smith-Vaughan H.C., Sriprakash K.S., Leach A.J., et al. Low genetic diversity of Haemophilus influenzae type b compared to nonencapsulated $H$. influenzae in a population in which $H$. influenzae is highly endemic. Infect Immun 1998;66:3403-9.

41.Bouskela M.A.L., Grisi S., Escobar A.M.U. Aspectos epidemiologicos da infecção por Haemophilus influenzae tipo b. Rev Panam Salud Publica 2000; 7:332-9.

42. Barbour M.L., Mayon-White R.T., Coles C., et al. The impact of conjugate vaccine on carriage of Haemophilus influenzae type b J Infect Dis 1995; 171:93-8. 
43. Muhlemann K., Balz M., Aebi S., Schopfe K. Molecular characteristics of Haemophilus influenzae causing invasive disease during the period of vaccination in Switzerland: analysis of strains isolated between 1986 and 1993. J Clin Microbiol 1996;34:560-3.

44. Tsolia M.N., Theodoridon M.N., Mostron G.J., et al. Epidemiology of invasive Haemophilus influenzae type b infections among children in Greece before the introduction of immunization. Scand J Infect Dis 1998;30:165-8.

45. Scheifele D.W., Halperin S.A., Guasparini R., et al. Extended follow-up of antibody levels and antigen responsiveness after 2 Haemophilus influenzae type b conjugate vaccines. J Pediatr 1999; 135:240-5.

46. Murphy T.V., Granoff D., Chrane D.F., et al. Pharyngeal colonization with Haemophilus influenzae type $\mathrm{b}$ in children in a day care center without invasive disease.J

Pediatr 1985; 106:712-6. 